\title{
Possible role of coronary spasm in acute myocardial infarction precipitated by hyperventilation
}

\author{
KYOJI TAKAOKA, HIROFUMI YASUE, YUTAKA HORIO \\ From the Division of Cardiology, Kumamoto University School of Medicine, Honjou, Kumamoto City, Japan
}

SUMMARY Acute myocardial infarction was precipitated by hyperventilation in a 65 year old mani His coronary arteriogram in the chronic phase showed almost normal coronary arteries. Injection of acetylcholine $(50 \mu \mathrm{g})$ into the left coronary artery induced spasm of the circumflex artery withi chest pain in association with ST-segment elevation in the inferior leads and ST-segmen? depression in the precordial leads.

In this patient there may have been atherosclerosis of the coronary arteries with absent or $\vec{T}_{T}$ dysfunctional endothelium, despite an almost normal angiographic appearance. In the absence of endothelium the response of the smooth muscle to acetylcholine is constriction.

Knowledge of the pathogenesis of acute myocardial infarction is still incomplete, but there is some evidence that coronary spasm has a role. ${ }^{1-3}$

We report a patient in whom an acute myocardial infarction was precipitated by hyperventilation and in whom intracoronary injection of acetylcholine induced coronary spasm in the chronic phase.

\section{Case report}

A 65 year old man was admitted to our hospital because he had a syncopal attack. He had been well

Requests for reprints to Dr Hirofumi Yasue, Division of Cardiology, Kumamoto University School of Medicine, 1-1-1 Honjou, Kumamoto City 860, Japan. and had had no chest pain until three months before $e_{\infty 0}^{\circ}$ when he had a syncopal attack lasting a few minutes after an operation on his hand. He had appreciable bradycardia but no chest pain at the time.

On admission the electrocardiogram showed sinus bradycardia but no ST-segment changes. He was asked to hyperventilate for an electroencephalogra phic test to investigate the syncopal attack. A fewo minutes after hyperventilating he felt chest discom fort which developed into chest oppression lasting more than an hour. The electrocardiogram taken at: that time showed considerable ST-segment depres $\widetilde{\widehat{\sigma}}$ sion in leads II, III, aVF, and V2-V6 and an increase in serum creatine kinase to $356 \mathrm{IU}$ (normal range $32 \odot$ 166 IU for men in our laboratory). Non-transmura myocardial infarction was diagnosed. A month late

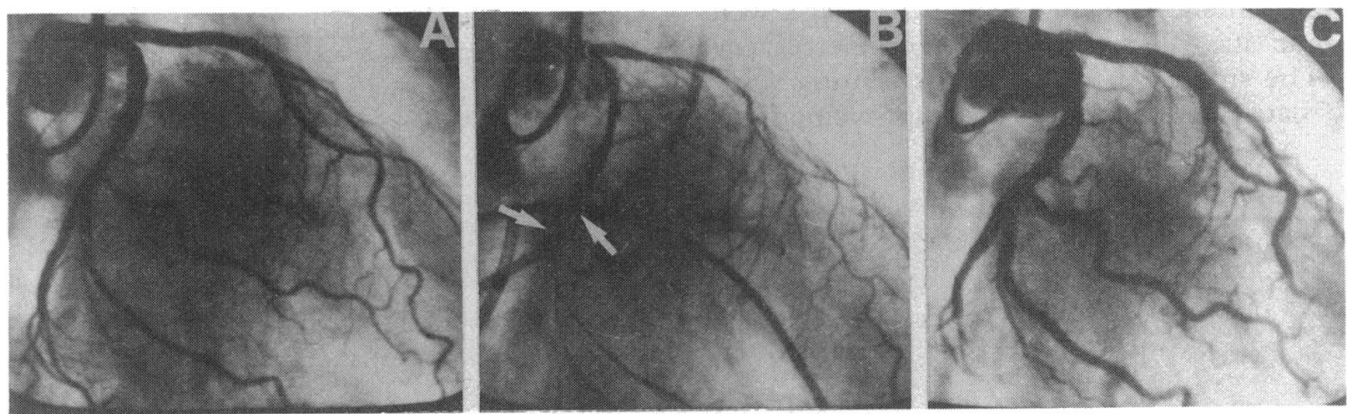

Fig 1 Left coronary arteriograms before and during an attack of chest pain induced by injection of acetylcholine $(50 \mu \mathrm{g})$ into the left coronary artery and after the administration of glyceryl trinitrate. (a) Left coronary arteriogram before injection of acetylcholine. (b) Two minutes after injection of acetylcholine the obtuse marginal branch and posterior descending artery (white arrows) were occluded and were not visualised. (c) After administration of glyceryl trinitrate the coronary artery was considerably dilated and almost normal. 

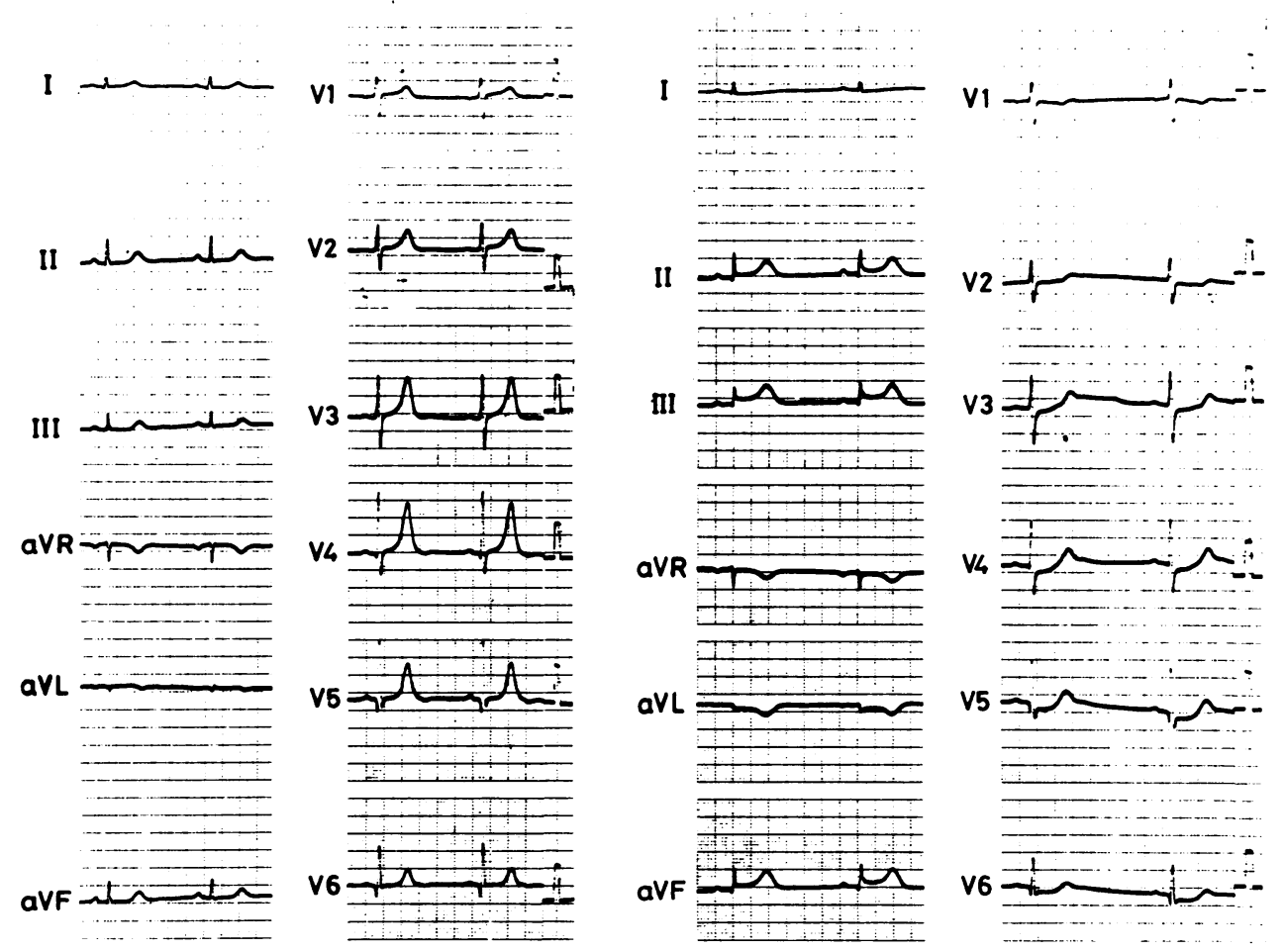

Fig 2 (a) Electrocardiogram before intracoronary injection of acetylcholine shows sinus bradycardia but no STsegment changes. (b) Electrocardiogram after injection of acetylcholine ( $50 \mu \mathrm{g}$ ) into the left coronary artery shows $S T$-segment depression in the precordial leads and ST-segment elevation in leads II, III, and aVF.

cardiac catheterisation was performed. Coronary angiography, measurement of coronary sinus blood flow by thermodilution, and blood sampling were performed before and after intracoronary injection of acetylcholine. Baseline aortic blood pressure, coronary sinus blood flow, the myocardial lactate extraction ratio, and coronary vascular resistance were $165 /$ $76 \mathrm{~mm} \mathrm{Hg}, 78 \mathrm{ml} / \mathrm{min}, 6.6 \%$, and $1346 \mathrm{~mm} \mathrm{Hg} \mathrm{min} / 1$ respectively. Before the administration of acetylcholine coronary angiography showed normal right and left coronary arteries with a dominant left circumflex artery giving rise to the posterior descending artery (fig 1a). Two minutes after the injection of acetylcholine $(50 \mu \mathrm{g})$ into the left coronary artery there was ST-segment elevation in leads II, III, and aVF and ST-segment depression in leads V2-V6 (fig 2) and the patient complained of chest pain. Aortic pressure fell to $109 / 50 \mathrm{~mm} \mathrm{Hg}$ and myocardial lactate extraction fell to $-69 \cdot 4 \%$. Nevertheless, coronary sinus blood flow increased to $150 \mathrm{ml} / \mathrm{min}$ and coronary vascular resistance fell to $433 \mathrm{~mm} \mathrm{Hg} \mathrm{min} / 1$. Coronary arteriograms showed occlusion of the obtuse marginal branch and posterior descending artery of the left circumflex artery and diffuse constriction of the other segments of the left coronary artery (fig 1b). The attack and spasm disappeared after intracoronary injection of glyceryl trinitrate $(200 \mu \mathrm{g})$ which caused considerable dilatation of the coronary artery (fig 1c).

\section{Discussion}

The attack of acute myocardial infarction in this patient was precipitated by hyperventilation and, because hyperventilation can induce coronary spasm in patients with variant angina, ${ }^{4}$ it is possible that coronary spasm precipitated acute myocardial infarction in this patient. This theory is supported by the almost normal coronary arteriogram in the chronic phase and the induction of spasm of the circumflex artery (associated with ST-segment deviations in the inferior and precordial leads) and chest pain by intracoronary injection of acetylcholine.

Thus this report shows that hyperventilation may precipitate acute myocardial infarction, possibly by inducing coronary spasm in some patients. There are 
also reports of death associated with hyperventilation. ${ }^{56}$ This fact is clinically important because hyperventilation is routinely performed in the electroencephalographic or ventilatory tests.

Injection of acetylcholine is generally accepted as causing coronary vasodilatation, as shown by increased coronary blood flow. ${ }^{7}$ In our patient coronary sinus blood flow increased and coronary vascular resistance decreased after injection of acetylcholine, despite the occurrence of spasm of the left coronary artery producing myocardial ischaemia (shown by ST-segment deviations in the electrocardiogram), a decreased myocardial lactate extraction ratio, and chest pain. We propose the following explanation of this paradox: myocardial ischaemia occurred in the region of the left circumflex artery only; intracoronary injection of acetylcholine induced spasm or constriction of epicardial arteries but dilated the resistance vessels and arterioles; and the flow in the area of myocardium perfused by the artery occluded by spasm may have been decreased but the flow in other parts of myocardium may have been increased, so that the total coronary flow increased.

The present study shows that acetylcholine constricts human epicardial coronary artery in vivo and may cause coronary spasm in some patients. Recently, Furchgott and Zawadzki reported that acetylcholine can reproducibly relax arterial strips in vitro if care is taken to preserve the endothelium during preparation of the strips. ${ }^{8}$ Contraction was observed only when the endothelium was inadvertently removed, suggesting that in the absence of endothelium the direct response of the smooth muscle is contraction. A factor that initiates the relaxation of vascular smooth muscle is released by the endothelial cells when they are exposed to acetylcholine, ${ }^{8-10}$ and endothelial injury and proliferation of smooth muscle cells are essential in the pathogenesis of atherosclerosis. ${ }^{11}$ It is thus possible that in this patient there was atherosclerosis of the coronary arteries with absent or dysfunctional endothelium, despite an almost normal angiographic appearance. We and Ludmer $e t$ al reported that intracoronary injection of acetylcholine induced coronary vasoconstriction if. almost all adults, probably because most of then have atherosclerosis. ${ }^{12} 13$

\section{References}

1 Oliva PB, Breckinridge JC. Arteriographic evidence of coronary arterial spasm in acute myocardial infarc $\mathscr{S}$ tion. Circulation 1977;56:366-74.

2 Maseri A, L'Abbate A, Baroldi G, et al. Coronaryvasospasm as a possible cause of myocardial infarc $\epsilon$ tion. A conclusion derived from the study "preinfarc $ᄋ$ tion" angina. N Engl J Med 1978;299:1271-7.

3 Yasue H, Omote S, Takizawa A, et al. Acute myocardiai infarction induced by ergotamine tartrate: possible role of coronary arterial spasm. Angiology $1981 \mathrm{~N}$ 32:414-8.

4 Yasue $\mathrm{H}$, Omote $\mathrm{S}$, Takizawa A, et al. Coronary arteriab spasm and Prinzmetal's variant form of angina induced by hyperventilation and Tris-buffer $_{\text {T }}$ infusion. Circulation 1978;58:56-62.

5 Bates JH, Adamson JS, Pierce JA. Death after volun tary hyperventilation. $N$ Engl J Med 1966;274:13712.

6 Bouras N, Kartsounis LD, Bridges PK. Death asso $\overrightarrow{0}$ ciated with hyperventilation. Lancet 1987;i:635-6.

7 Levy MN, Zieske H. Comparison of the cardiac effect of vagus nerve stimulation and of acetylcholine infusions. Am J Physiol 1968;216:890-7.

8 Furchgott RF, Zawadzki JV. The obligatory role of endothelial cells in the relaxation of arterial smootho muscle by actylcholine. Nature 1980;288:373-6.

9 De May JG, Claeys M, Vanhoutte PM. Endothelium $\vec{F}$ dependent inhibitory effects of acetylcholine, aden $\frac{\text { O }}{3}$ osine triphosphate, thrombin and arachidonic acid in the canine femoral artery. J Pharmacol Exp The 1982;222:166-73.

10 Anonymous. EDRF. Lancet 1987;ii:137-8.

11 Ross R, Glosmet JA. The pathogenesis of athero sclerosis. N Engl J Med 1976;295:369-77.

12 Horio $\mathrm{Y}$, Yasue $\mathrm{H}$, Rokutanda $M$, et al. Effects of intracoronary injection of acetylcholine on coronaryo arterial diameter. Am J Cardiol 1986;57:984-9.

13 Ludmer PL, Selwyn AP, Shook TL, et al. Paradoxical vasoconstriction induced by acetylcholine in athero- $-\frac{\mathrm{P}}{\mathrm{T}}$ sclerotic coronary arteries. N Engl J Med 1986 315:1046-51. 